\title{
EL PRINCIPIO MORAL DEL MAL MENOR FRENTE AL PROBLEMA de la narCo-VIOLEnCIa en MÉxico
}

Juan Auping Birch, SJ

Universidad Iberoamericana, México

jauping@iwm.com.mx

Resumen

En este trabajo se explora una aplicación del principio moral del "mal menor" a un problema práctico, el de la violencia por el narcotráfico en México. En la primera parte se explican y se discuten las tesis de santo Tomás de Aquino acerca de este principio. En la segunda parte se analizan los distintos elementos del problemá práctico y, por último, se ofrece una propuesta de decisión prudencial a partir de un principio filosófico.

Palabras clave: ética, filosofía práctica, mal menor, moral, violencia. 


\section{The Moral Principle of the Lesser Evil Against the Problem of Narco-Violence in Mexico}

Abstract

This work reflects on the principle of "lesser evil" and presents an application of this moral principle to a practical problem, the violence caused by drugtraffic in Mexico. In the first part, it explains the main thesis of St. Thomas Aquinas on the moral principle of the "lesser evil". On the second part, it analyses the different aspects of the practical problema and, at the end, proposes a pruential solution on a moral philosophy basis.

Keywords: Ethics, Lesser Evil, Morals, Practical Philosophy, Violence. 


\section{Introducción}

La historia humana, en el fondo, es una lucha entre el bien y el mal. Los que hacen el mal engañan, mienten, chantajean, oprimen, roban y matan, violando los Derechos Humanos. La no-violencia es una manera, entre otras, de que personas y gobiernos, en determinadas circunstancias, se enfrenten al dominio del mal para vencerlo.

Hay realmente dos maneras de practicar la no-violencia, según las circunstancias:

1. Hacer valer nuestros Derechos Humanos frente al opresor, dispuesto a pagar el precio del sufrimiento con el fin de acabar con el dominio del mal: se llama la resistencia no-violenta y activa; generalmente es usada contra el mal practicado por el Estado, cuando viola Derechos Humanos de los ciudadanos, y a veces es usado también contra el abuso de grandes empresas.

2. Permitir un mal menor con el fin de prevenir o terminar un mal mayor; se llama la no-violencia pasiva y generalmente es usado por el Estado u otra autoridad contra el mal practicado por ciudadanos o súbditos.

En este ensayo presento mi propuesta para una estrategia no violenta pasiva del Estado contra el narco, en México, basado en el principio del mal menor.

\section{La ética de la no-violencia pasiva: el principio del mal menor}

La no-violencia pasiva es un tipo de tolerancia. Según el diccionario, ${ }^{1}$ el significado del término tolerancia es "acción y efecto de tolerar", y tolerar quiere decir tanto "sufrir o llevar con paciencia", como "permitir algo que no se tiene por lícito, sin aprobarlo expresamente". En el orden práctico, esta tolerancia implica que se permite alguna

1 Diccionario de la Lengua Española. 
acción mala de una persona o un grupo, sin aprobarla ni colaborar en ella. En el orden del pensamiento la tolerancia permite la divulgación del error, sin aprobarlo.

Existen dos tipos de tolerancia con respecto a las acciones malas de personas o grupos. La primera es la falsa tolerancia, que permite que se practique el mal pudiendo impedirlo sin provocar un mal mayor. Esta falsa tolerancia nos hace cómplices del mal por nuestra pasividad y omisión. La resistencia no-violenta y activa rechaza la falsa tolerancia, y trata de resistir y combatir el mal de manera noviolenta con el fin de erradicarlo.

Sin embargo, existe otro tipo de tolerancia, recta, hacia el mal, a saber, la que permite conscientemente que se lleve a cabo o que persista un mal menor, porque el intento de reprimirlo por la fuerza pública provocaría un mal mayor. Se trata del principio del mal menor, bien entendido. ${ }^{2}$ Santo Tomás de Aquino lo aplica al divorcio permitido en la antigua ley de Moisés, el cual fue un mal menor para prevenir un mal mayor, a saber, el de matar a las esposas acusadas de adulterio: "Con lo dicho se excluye la costumbre de repudiar a las esposas. Si fue permitido en la vieja ley a los judíos -por su dureza-, fue por ser proclives a matarlas. Se permitió el menor mal para excluir el mayor" (Summa contra gentiles, III, 123).

En general así argumenta santo Tomás, la Divina Providencia permite el mal porque de reprimir el mal en este mundo creado, desaparecería el bien: "El mal no existiría si desapareciera el orden del bien, cuya privación es el mal.Y tal orden no existiría si Dios no existiera [...] el mal y el defecto ocurren en las cosas gobernadas por la divina providencia, dada la condición de las causas segundas" (Summa contra gentiles, III, 71).

Asimismo, al crear el mundo y al encarnarse el Verbo para morir en la cruz, Dios permitió males menores (los pecados de los hombres) para obtener un bien mayor (la eterna felicidad de muchos) e impedir un mal mayor (la perdición de todos): "aunque hayan nacido algunos errores en torno a la encarnación, [...] sin embargo, está

2 En este apartado 3.1 me apoyo, desde luego en Santo Tomás de Aquino y en las reflexiones de Fernando Cuervo Valseca (1994) y Francisco Fernández Sánchez (2004). 
claro que muchos más fueron destruidos después de ella, [...] así como de la creación de las cosas, procedente de la bondad divina, se siguieron algunos males debidos a la condición de las criaturas, que son falibles" (Summa contra gentiles, IV, 55).

Así, de manera concisa, confirma santo Tomás, "un legislador sabio permite el mal menor para evitar el mal mayor" (Summa theologica, I, q. 48, a. 6) y que "no es justo destruir el bien común para evitar un mal particular" (Summa theologica, I, q. 92, art. 2). Según santo Tomás, al practicar esta tolerancia, la autoridad sigue el ejemplo del mismo Dios:

El gobierno humano proviene del divino. Pues siendo Dios omnipotente y sumamente bueno, permite sin embargo que sucedan males en el universo pudiéndolos impedir, no suceda que suprimiendo estos males, queden impedidos bienes mayores o incluso se sigan mayores males. Así pues en el gobierno humano quienes gobiernan toleran también razonablemente algunos males para no impedir otros bienes o incluso para evitar mayores males (Summa theologica, II-II, q. 10, art. 11).

Una aplicación de este principio del mal menor es la tolerancia y la regulación por el Estado de la prostitución, como afirman san Agustín y santo Tomás: "Así lo afirma san Agustín en De Ordine: Quita a los meretrices de entre los humanos y habrás turbado todas las cosas con sensualidades" (Summa theologica, II-II, q. 10, art. 11).

Mal se entendería este principio si se afirmara que es lícito cometer un mal menor para obtener un bien mayor (DeVeritate, q. 5, art. 4). Lo mismo afirma el Papa Pablo VI, a saber, que en ciertas circunstancias "es lícito [...] tolerar un mal moral menor a fin de evitar un mal mayor o de promover un bien más grande”, quedando en pie, por supuesto, que "no es lícito, ni aun por razones gravísimas, hacer el mal para conseguir el bien” (HumanaeVitae, n. 14).

Por lo tanto, en ciertas circunstancias siguiendo la recta aplicación del principio del mal menor, el Estado no resiste el mal activamente, ni lo penaliza, sino permite un mal menor, sin aprobarlo, con el fin de evitar o eliminar un mal mayor. 
Veamos un ejemplo histórico de la recta aplicación de este principio, a saber, la prohibición del alcohol en los EUA, con el uso de la fuerza pública contra los traficantes ilegales de bebidas alcohólicas de 1920 a 1933, y la revocación de esta prohibición en 1933. Como la gente no estaba de acuerdo con la prohibición, había un desacato generalizado de la ley. Se seguía consumiendo alcohol, pero con una diferencia respecto a la era anterior cuando el tráfico y consumo de alcohol estaban permitidos: bajó el consumo de bebidas de contenido alcohólico bajo y aumentó considerablemente el consumo de bebidas de alto contenido alcohólico (Warburton, 1932; Ferragut, 2010: p. 257). En los tres primeros años de la prohibición se desplomó el consumo de bebidas alcohólicas, pero a partir del tercer año empezó a recuperarse y en los años 1929 y 1930, el consumo de cerveza casi alcanzó el nivel de 1919, mientras el consumo de vino, licores y alcohol puro durante la era de la prohibición, llegó a rebasar el consumo durante la era del consumo legal, en un $75 \%$, un $142 \%$ y un $64 \%$, respectivamente. De esta manera se derrotó en los hechos la meta principal de la prohibición, a saber: la reducción del consumo de alcohol. Al incrementarse considerablemente el consumo de bebidas de alto contenido alcohólico, aumentó también el alcoholismo como enfermedad.

Rápidamente, el tráfico ilegal por bandas criminales, como la de Al Capone en Chicago, empezó a tomar el lugar de las anteriores empresas legales, generando ganancias astronómicas y desatando la violencia por la competencia entre diferentes bandas y la guerra contra ellas por el Estado y de ellas contra el Estado. Aumentó considerablemente la fabricación ilegal de bebidas alcohólicas alteradas, incrementando significativamente el daño a la salud.

La prohibición del alcohol en los EUA no logró la reducción de bebidas alcohólicas y, además, generó una violencia desbordada y mayores daños a la salud pública. Esta es la razón por la cual las mismas personas - entre ellas John Rockefeller-, que antes habían abogado por la prohibición de las bebidas alcohólicas a principios de los años '30, abogaban ahora por la legalización de su compra-venta. El Estado volvió a permitir un mal menor, quitando y previniendo así un mal mayor. 
2. El mal mayor: los miles de muertos y el inmenso poder corruptor del narco

Para entender la validez de la aplicación del principio del mal menor a la narco-violencia en México, hemos de definir primero en qué consiste el mal mayor. La guerra contra el narcotráfico que México empezó en diciembre de 2006 ha sido particularmente sangrienta porque ha costado, de diciembre de 2006 a 2015, unos 80,000 muertos por los conflictos entre diferentes bandas de narcotraficantes y con las fuerzas públicas, entre ellos soldados y policías que han muerto en el cumplimiento de su deber. Son recurrentes las masacres masivas: los 22 de Tlatlaya; los 43 de Ayotzinapa; los 72 de San Fernando; los 15 de Villas de Salvárcar, algunos perpetrados por el crimen, otros por las fuerzas de seguridad, y otros por ambos en colaboración. Entre estos muertos se encuentran más de 4,000 niños, adolescentes y jóvenes, y además el padre y/o la madre de miles y miles de niños y adolescentes que quedaron huérfanos de padre $\mathrm{y} / \mathrm{o}$ madre, generando un total de más de 20,000 familias afectadas.

En el 60\% de los municipios del país, la policía municipal está siendo controlada o infiltrada en medida suficiente por el narco para que éste logre su objetivo de controlar la política de seguridad del municipio. Existen 165,500 policías municipales, a quienes se paga un sueldo de hambre. Ninguna familia de cinco personas puede vivir dignamente de $\$ 5,000$ a $\$ 6,000$ mensuales. ${ }^{3}$ Por eso, son susceptibles de aceptar un ingreso adicional del narco, que nivela el déficit salarial de policías municipales, gastando en este concepto unos mil doscientos millones de pesos mensuales.

El alcalde que no colabora, se juega la vida. Plomo o plata. Hasta la fecha, casi 20 presidentes municipales han sido asesinados por el narco. Sabiendo los presidentes municipales de muchos municipios que pueden ser asesinados, optan por no apretar demasiado al narco y la policía municipal y por nombrar directores o comandantes municipales de seguridad sugeridos o permitidos por el narco y de alguna manera permitir el tránsito de cargamentos de droga por su territorio municipal. Obviamente, estos presidentes municipales no

3 En Guadalajara $\$ 6,000$. En el DF, $\$ 8,000$. 
reportan al gobierno federal qué es lo que exactamente están haciendo o dejando de hacer en este campo de la lucha contra el narcotráfico. Otros gobernadores y alcaldes se alían descaradamente al narco y forman parte de la creciente narco-democracia en México. Un caso reciente (septiembre de 2014) es el de José Luís Abarca, alcalde de Iguala, y su esposa María de los Ángeles Pineda, que entregaron a 43 normalistas al cártel de Guerreros Unidos para que fueran asesinados.

Asimismo, están siendo infiltrados o chantajeados los ministerios públicos en muchos municipios, y representantes del poder judicial en el Norte del país han admitido públicamente que se encuentran incapacitados para dar seguimiento a la persecución de ciertos delitos relacionados con el narco, como por ejemplo la matanza de jóvenes en discotecas de la Comarca Lagunera, desde el Cereso Dos de Durango, porque la integridad física de los jueces y sus familias no tienen garantías suficientes. También los Ceresos y cárceles están siendo infiltrados por el crimen organizado y, sobre todo, el narco.

Simultáneamente, muchos negocios - en todo el territorio nacional y no solamente en el Norte del país-, pagan el "derecho de piso". Un ejemplo es el caso de Iguala durante el régimen de terror de Abarca y Pineda. La organización criminal Guerreros Unidos, desde 2011, armó una red de cobros de piso y de "protección" de la cual no se salvó casi nadie. Los taxis y el comercio fueron de los principales atractivos para la delincuencia. Negarse a pagar la extorsión equivalía a represalias, incluidos el secuestro y el homicidio, reconocieron los afectados. Puestos de comida, churrerías, tiendas de ropa, estéticas, cervecerías, taquerías, restaurantes y abarrotes, entre otros, pagaron a la delincuencia de 40 pesos diarios a mil 200 a la semana para que "sus negocios estuvieran seguros". Ganaderos, gasolineros y dueños de bares daban hasta cinco mil pesos semanales. Ante esto, un gasolinero decidió irse de Iguala, pero fue secuestrado en 2013 y luego desaparecido cuando escapaba hacia Chilpancingo, coinciden versiones de empresarios. Entre 2013 y junio de 2014, unos siete taxistas desaparecieron tras negarse a pagar, y otra decena de comerciantes fueron secuestrados para obligarlos a pagar, revelaron víctimas. 
Muchos negocios en el país pagan impuestos dos veces, entonces: al Estado que no los protege, y al narco que los extorsiona. Los negocios que pagan derecho de piso no suelen acudir al poder judicial para denunciar estos hechos porque significaría en muchos casos la muerte. No se necesita tener un doctorado en economía para entender lo que esto significa para la economía del país y los ingresos de los negocios y el bienestar de muchas familias. En las encuestas sobre los índices de competitividad, el Foro Económico Mundial (WEF) aclara que el grado de afectación del mundo de los negocios por el crimen organizado coloca a México en el lugar 136, solamente rebasado por Colombia (137), Guatemala (138) y El Salvador (139).

Hemos de preguntarnos ¿de dónde viene el poder económico del narco para corromper a la sociedad y la autoridad? ¿Cómo pueden pagar mil doscientos millones de pesos mensuales a la policía municipal; hacer otras derogaciones cuantiosas, como las relacionadas con el transporte de droga ilícita a los EUA, reaccionando creativamente a los avances del Estado al encontrar siempre nuevas maneras de transporte; corromper a funcionarios públicos también a nivel estatal y federal; comprar grandes cantidades de armas, como el AK-47, al otro lado de la frontera y camionetas y departamentos y casas de lujo?

El poder corruptor y destructivo del narco se deriva de sus astronómicos ingresos. El narco mundial gana anualmente entre $300 \mathrm{y}$ 400 mil millones de dólares. En México, el crimen organizado gana entre 38 y 56 mil millones de dólares anuales, de los cuales el 75\% es ganancia del narcotráfico. ¿Cómo puede el narco ganar tanto dinero? La respuesta es un tanto paradójica: gracias a la guerra del Estado contra el narcotráfico, éste obtiene ganancias multimillonarias. Hemos de analizar esta paradoja, que es primordial para entender la crisis por la cual atraviesa México.

El precio de la droga es elevado. Un paciente mío fue adicto a la coca. Compraba más o menos cada otro día una "grapa" de coca, que contiene medio gramo de coca ya procesada, por doscientos pesos. Con este dato, el lector puede darse una idea de cuánto es el ingreso por la venta de un kilo de coca de buena calidad: $\$ 2000 * \$ 200=\$ 400,000$, ¡cuatrocientos mil pesos! En cambio, ¡en los EUA, el precio de un 
gramo de coca es de 200 dólares, de modo que allí un kilo a menudeo vale más de diez veces más que en México, a saber, unos USD $\$ 200,000$, el equivalente de unos 2.4 millones de pesos! (Ferragut, 2010). En los EUA el precio de la droga es mucho mayor que en México, en primer lugar, porque la demanda es mucho mayor -la curva de demanda se mueve a la derecha-; y en segundo lugar porque el costo de introducir la droga al país es mayor. De la droga consumida en América del Norte, los EUA consumen el 88\% de heroína, el 89\% de cocaína, el 88\% de marihuana, el 93\% de anfetamina, el 91\% de éxtasis; y México y Canadá todo lo restante (ONU, 2005).

La demanda de droga en México no varía con el modo de combatirlo. Este es el argumento empírico de Aguilar y Castañeda (2009): el consumo de droga en México disminuía cuando no había guerra contra el narco, y aumentó en el período en que la guerra contra la droga había iniciado en diciembre de 2006. La demanda de droga es inelástica, es decir: la cantidad demandada no varía con el precio. Los economistas entienden esto, pero los no-economistas tal vez no lo entiendan muy bien. Por eso, explico un poco la gráfica que presentaré a continuación. Una curva de demanda representa el conjunto de combinaciones de niveles de precios y cantidades demandadas: a mayor precio, menor cantidad demandada. Sin embargo, en el caso de la droga, la demanda es inelástica y por eso la curva tiene una posición casi vertical. Esto quiere decir que los adictos a la droga demandan su droga independiente del nivel de precios de la misma. Por eso se llaman adictos: requieren su dosis a como dé lugar y al precio que sea. La guerra contra la droga ilícita no ha impedido que en México, al igual que en los EUA, el consumo de droga ilícita aumente. En general, la penalización de algunas drogas o bebidas alcohólicas no cambia la tasa de adicción. Estas tasas de adicción/dependencia son $66 \%$ de los consumidores para la heroína, 28\% para la cocaína, $18 \%$ para la marihuana, y $12 \%$ para éxtasis, anfetaminas y alcohol.

Una curva de oferta es el conjunto de niveles de precios y cantidades ofrecidas: a mayor precio, mayor cantidad ofrecida. Tiene una inclinación normal. Pero, por el combate a la droga ilícita, la curva de oferta se desplaza a la izquierda porque las personas normales se retiran de negocio, dejando el campo abierto a unos cuantos 
sociópatas. Esto quiere decir que en cada nivel de precios, la cantidad de oferentes de droga ilícita es mucho menor que la cantidad de oferentes de droga lícita.

Donde las curvas de oferta y demanda se cruzan, está el equilibrio de demanda y oferta en el mercado. La característica peculiar del mercado de drogas es que, por el combate a la droga ilícita, la curva de oferta se mueve a la izquierda, cruzando la curva de demanda, que es inelástica, más arriba. En consecuencia, el fruto del combate violento a la compraventa de droga ilícita es que aumenta astronómicamente el precio de la droga, sin que disminuya la cantidad demandada y ofrecida.

Esto es lo que realmente vemos en México y en los EUA: por el combate violento del Estado contra la droga ilícita, las utilidades de las bandas de narcotraficantes llegan a ser astronómicas, por el nivel de precios tan alto de la droga ilícita y, sin embargo, la cantidad demandada y ofrecida de droga ilícita, comparada con la de droga lícita, casi no se reduce. Los ingresos astronómicos del narco, obtenidos gracias al hecho que el Estado empuja la curva de oferta a la izquierda por su guerra contra el narco, los usa para vivir en lujos, pagar sus sicarios y corromper alcaldes, gobernadores, policías, miembros del ejército y otros servidores públicos; en otras palabras, para corromper el Estado.

\section{CURVAS DE DEMANDA Y DE OFERTA DE DROGA LEGAL E ILEGAL}

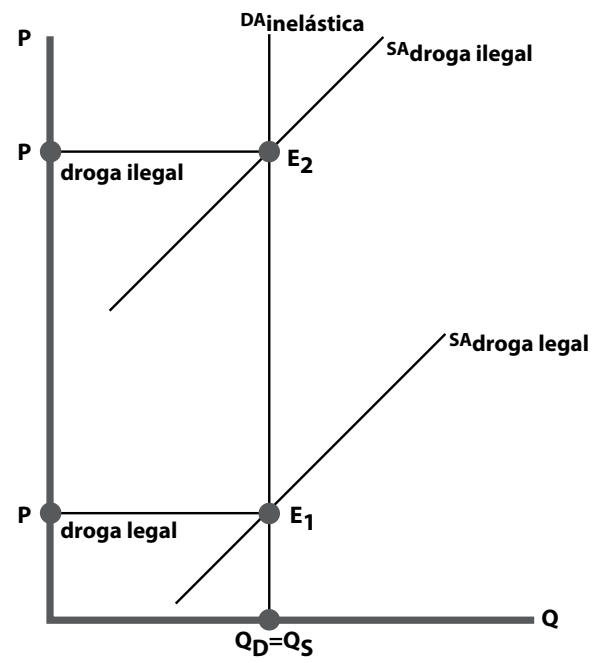


Las bandas de narcotraficantes lavan sus astronómicos ingresos, ya sea por el modelo de honorarios, por transacciones de acciones u operaciones de bienes inmuebles, "con un riesgo mínimo o sin riesgo" (Ferragut, 2010: p. 192). La venta al menudeo de droga ilícita en los EUA arroja ingresos de unos 125 mil millones de dólares anuales. Entre $67 \%$ y $70 \%$ de estos ingresos son lavados dentro de los EUA y el 22\% en México (Ferragut, 2010: p. 193). Ferragut calcula que en un plazo de veinte años, una cantidad inicial de 100 mil millones de dólares se convierten en 80 mil millones de dólares para el narco, 97 mil millones de dólares para el socio 'legal' del narco y 36 mil millones de dólares para el fisco de los EUA (Ferragut, 2010: cap. 4; Apéndice B).

La encarcelación o muerte de muchos sicarios al servicio de diferentes bandas de narcotraficantes solamente debilitaría al narco si éste no pudiera reclutar a nuevos jefes y sicarios. Lamentablemente, la oferta de potenciales narcotraficantes y sicarios es muy grande: 7.5 millones de "ninis", de los cuales seis millones y medio son hombres, la policía municipal, estatal y judicial (y otros cuerpos de seguridad) mal pagadas, y los inmigrantes de Centro América, de los cuales las bandas de narcotraficantes, mediante corrupción y chantaje, reclutan nuevos sicarios. Si la tasa de eliminación de sicarios y narcotraficantes rebasara la tasa de reclutamiento, habría esperanza de éxito en el largo plazo pero, en los hechos, se da el caso contrario.

\section{Cuatro maneras históricas de combatir la drogadicción y el narcotráfico}

En este apartado veremos cuatro formas de combatir la droga que, históricamente, se han puesto en marcha: a) la liberalización de la droga sin regulación ni control de las autoridades; b) la guerra contra la droga en un régimen totalitario; c) la guerra contra la droga ilícita en una democracia; d) la legalización con regulación y control por las autoridades.

La primera manera. Los poderes coloniales, sobre todo los británicos, promovieron y capitalizaron la producción y el tráfico de opio, 
promoviendo el consumo, en los siglos XVIII, XIX y a principios del siglo XX, haciéndose de ganancias astronómicas, como hoy día las del narcotráfico ilícito. Durante algún tiempo, los británicos tuvieron el monopolio de este negocio, elevando el precio para su propio beneficio, pero lo perdieron entrando al siglo XIX, inaugurando la era de la legalización liberal, sin regulación ni control. Rápidamente se extendió la adicción al opio, primero a China, donde alcanzó a unos 30 millones de chinos en la primera mitad del siglo XX, luego al resto de Asia, Europa y los EUA. El volumen máximo de producción y comercialización de opio se alcanzó en 1907, unas 41,000 toneladas, 10 veces la cantidad actual.

Si evaluamos esta experiencia, podemos decir que fue 100\% exitosa en prevenir la violencia asociada a la droga ilícita, pero un fracaso total en cuanto la meta de reducir o eliminar la adicción a la droga (Ferragut, p. 315).

La segunda manera. Bajo el régimen totalitario de Mao Tse Tung, China superó en los años ' 50 del siglo XX el problema de la adicción al opio. Los traficantes eran fusilados ante el paredón, y los 30 millones de adictos fueron obligados a integrarse en un programa de rehabilitación forzosa. En pocos años el problema desapareció. Evaluando esta experiencia, podemos decir que alcanzaron el primer objetivo, de la eliminación del abuso de droga dañina y acabaron también con la violencia asociada al tráfico de droga ilícita - sin tomar en cuenta los miles de fusilamientos-, pero pagando el precio de la total eliminación de los procesos democráticos y los Derechos Humanos.

La tercera manera. Los resultados de la prohibición actual de drogas ilícitas en los EUA es igualmente un fracaso, así como lo fue la prohibición de bebidas alcohólicas de 1920 a 1933. En septiembre de 2010 salió la última Encuesta Nacional sobre Uso de Drogas y Salud de los EUA. Según esta encuesta, en el año 2009, fue rebasado el anterior máximo histórico del consumo de drogas en los EUA, de 2002.

En México, el fracaso rotundo de la guerra contra la droga ilícita fue explicado arriba, en el apartado 3.1. Hubo una mínima reforma, mal planteada. Si bien, la producción y compraventa de droga ilícita 
y el lavado de dinero son castigados, según el artículo 194 del Código Penal Federal, con 10 a 25 años de prisión se hizo una reforma al Código Penal Federal de México, en el sentido de despenalizarse la posesión de cantidades mínimas de drogas ilícitas para consumo personal, pero, se aplica por una sola vez y excluye a los fármaco-dependientes, a los cuales se sigue tratando como criminales y no como enfermos que son (Código Penal Federal: tit. VII., cap. 1, art, 194), cuando son precisamente los adictos a los que se debe tratar como enfermos y no como criminales, como vemos en seguida.

La cuarta manera. Existen algunos precedentes históricos de la legalización parcial controlada de droga ilícita con regulación y control por las autoridades, a saber: los casos históricos de Holanda, Portugal y Suiza. Una parte esencial de un programa de legalización es tratar a los adictos como enfermos, no como criminales, como veremos a continuación.

En Holanda se pusieron en práctica, desde 1976, las siguientes políticas: se distinguen soft drugs (sobre todo marihuana y haschich) de hard drugs (sobre todo, cocaína y heroína) y se busca desconectar la venta y el consumo de soft drugs de los ambientes viciosos y criminales donde se ofrecen hard drugs. Se tolera la producción casera de marihuana y se permite su consumo legal en los así llamados coffee shops de Amsterdam, tantas veces que el consumidor quiera, pero en cantidades diarias limitadas. Para prevenir la exportación de marihuana a otros países de la Unión Europea, dado el libre tránsito y la ausencia de controles en las fronteras, Holanda prohibió la venta de marihuana a extranjeros y se redujo la cantidad máxima que un holandés puede comprar en un día hasta 5 gramos de marihuana. Por lo demás, la compraventa de hard drugs sigue siendo ilegal. Por otro lado, se trata a los adictos como enfermos y no como criminales, despenalizando su consumo, y se les ofrece un tratamiento en programas de rehabilitación.

El European Monitory Centre for Drugs and Drug Addiction (EMCDDA) de la Unión Europea emitió en 1995 una interesante evaluación de la experiencia holandesa. Según este informe, quedó refutada la teoría de que los consumidores de soft drugs pasan 
automáticamente del consumo de soft drugs al consumo de hard drugs, la así llamada "stepping stone theory" (EMCDDA, 1995: p. 5).

De hecho, en Holanda, el número de adictos a hard drugs (unos $25,000)$, por cada mil personas de la población, está abajo de la media Europea de 2.7 y es de las más bajas de la Unión Europea, a saber, 1.6 por mil (EMCDDA, 1995: p. 6). El número de consumidores de drogas en Holanda está muy por abajo de los EUA, a saber, 5.4\% y $10.3 \%$ de la población consumen marihuana; $0.6 \%$ y $2.1 \%$, cocaina; y $0.0 \%$ y $0.2 \%$, heroína, respectivamente.

Portugal tenía en 1995 el segundo lugar en la tasa de adicción a drogas duras (hard drugs) más alta de Europa, a saber, 4.5 por mil habitantes. En 2001, Portugal decidió despenalizar totalmente la posesión de drogas, incluyendo marihuana, cocaína, heroína y metanfetaminas. Se sustituyó la cárcel por la oferta de rehabilitación, terapia y ayuda social y legal, respetando la libertad del adicto de aceptar esta oferta o no. Sin embargo, se mantuvo la penalización del tráfico de drogas. ¿Cómo ha funcionado esta política novedosa? Un estudio del Cato Institute encontró que durante los cinco años posteriores al inicio del programa, el uso de drogas ilícitas por adolescentes ha disminuido, la tasa de infección de VIH de adictos a hard drugs también ha disminuido, las muertes relacionadas con heroína y otras hard drugs han sido reducidas en un 50\%, y el número de personas que buscan ayuda se ha duplicado. En el mismo lapso, en los EUA, el uso y abuso de hard drugs siguió incrementando, incluyendo a los estados que tienen hardline drug policies, como Carolina del Norte (Greenwald, 2009).

Portugal tiene ahora la menor tasa de consumo de marihuana (las personas que alguna vez en su vida fumaron marihuana como proporción de la población total) de toda Europa, a saber, un 10\%. En los EUA es 40\%. Entre 2001 y 2006, las tasas de uso frecuente (no por una sola vez) de drogas en estudiantes del séptimo al noveno año escolar cayó de $14.1 \%$ al 10.6\%. Las tasas de consumo de heroína entre estudiantes de 16 a 18 años, se redujo en este lapso de $2.5 \%$ a $1.8 \%$. El número de personas dispuestas a entrar en programas de rehabilitación aumentó de 6,040 a 14,877 en este mismo lapso. 
Suiza era en 1995 el país europeo con la tasa más alta de adicción a drogas duras, a saber, 5.3 por mil habitantes. ${ }^{4}$ La experiencia de Suiza (Collin, 2002; Nadelmann, 1995: pp. 46-47) no es menos interesante que la de Holanda y Portugal. Después del fracaso de una legalización no controlada y no regulada, Suiza tuvo éxito con un segundo experimento. El objetivo fue el de sustituir el mercado ilegal de drogas por la prescripción médica legal y controlada. Este experimento encaja en los objetivos globales de la Unión Europea, a saber, combatir el tráfico ilegal de drogas, tratando a los adictos como enfermos, no como criminales. En 1991, el gobierno suizo adoptó un programa federal, basado en este concepto de "reducción de daño" (harm reduction), conocido como ProMeDro. Los objetivos de este programa eran a) disminuir el número de adictos a la droga y prevenir la adicción/ dependencia; b) ayudar a los adictos a superar su adicción y c) mejorar las condiciones de vida de los adictos e integrarlos en la sociedad.

En 1992, el Consejo Federal de Suiza autorizó experimentos clínicos, que incluyen la prescripción médica de heroína y la sustitución de heroína por metadona, acompañada por un riguroso programa de evaluación. Se abrieron los Fixerdume, o salones de inyección legal, donde los adictos pueden recibir su dosis en un ambiente higiénico y regulado. Una evaluación de 1997 de este experimento concluyó que el tratamiento con consumo de heroína previa receta médica para adictos mejoraba mucho su salud mental y física, así como su calidad de vida, por ejemplo, en términos de horas de trabajo y vivienda. El uso ilegal de heroína y cocaína se redujo significativamente y las personas incluidas en el programa cometieron menos crímenes para conseguir el dinero para conseguir la droga, como robo. Se redujo la compraventa ilegal de droga en una medida importante. El Consejo Federal siguió la recomendación de la comisión que hizo la evaluación de 1997 y autorizó en 1999 definitivamente los programas de prescripción médica de heroína, con terapia y ayuda social. Asimismo autorizó incrementar hasta mil el número de máquinas en el país donde, mediante una tarjeta de prescripción médica, los adictos pueden comprar su dosis legal: 800 para heroína, 100 para cocaína y 100 para metadona inyectable.

4 Es el promedio de dos estimaciones, a saber, 4 por mil y 6.7 por mil (EMCDDA, 1995: p. 6). 
Después de evaluar diferentes opciones, la Comisión Federal recomendó también unánimemente un marco jurídico que quitaba la prohibición y penalización de compraventa, posesión y consumo de marihuana (la producción ya era legal). Este modelo fue aprobado por el Senado suizo en diciembre de 2001, sin oposición alguna. Por encuestas se sabe que una mayoría de los ciudadanos suizos apoya la abolición de la prohibición de marihuana y si se hiciera un referendo al respecto, éste pasaría sin problema.

\section{La aplicación del principio del mal menor al problema de la narco-violencia}

La aplicación del principio del mal menor al problema del consumo y tráfico de drogas y al problema de la narco-violencia asociada con este problema, es diferente para soft drugs y para hard drugs. En ambos casos se trata de quitarle al narco sus ingresos astronómicos. En el caso de las soft drugs, esto se logra legalizando de manera controlada la producción y la compraventa de la droga, que estaría en manos de la iniciativa privada. En cambio, en el caso de las hard drugs, la estrategia consiste en dejar al Estado el monopolio de la provisión de la droga, así como el Estado tiene el monopolio de la provisión del circulante físico en la economía.

4.1. La aplicación del principio del mal menor al consumo y tráfico de soft drugs

En el caso de las soft drugs, especialmente la marihuana, el mal menor es la legalización controlada de la producción y la compraventa de la marihuana, dejando estas actividades en manos de la iniciativa privada bajo la ley reguladora y el control del Estado.

La marihuana es menos dañina ${ }^{5}$ y menos adictiva que el tabaco (Kandel, 1997). Solamente en México, cada año mueren 60,000 personas de tabaquismo y 40,000 de alcoholismo (25 mil en accidentes,

5 La marihuana contiene sustancias cancerígenas, pero son mucho menos potentes que la nicotina. 
15 mil por cirrosis). En la literatura sobre la marihuana no se conoce un solo caso de alguien que haya muerto por adicción a la marihuana, lo que no significa que ésta no tenga efectos negativos, sobre todo cierta falta de iniciativa y de memoria, pero es un mito que la adicción a la marihuana sea causa de psicosis (Iverson, 2005: pp. 6972; Andreasson, 1987: pp. 1483-1486; Degenhardt, 2003: pp. 4244). En México, en el 80\% de los casos de adicción, la enfermedad mental precede la adicción. La marihuana no crea dependencia física sino, en fumadores habituales, psicológica, que es fácil de superar con terapias (Stephens, 1993: pp. 1100-1104). En el consumo de dosis moderadas, la marihuana es como el alcohol: no surte efectos negativos y tiene efectos terapéuticos positivos. ${ }^{6}$

Es obvio que la marihuana debería legalizarse mundialmente y recibir el mismo tratamiento que bebidas alcohólicas y tabaco, es decir, prohibición de venta a menores, prohibición de consumo en escuelas, mensajes claros sobre los posibles riesgos en el empaque y tratamiento terapéutico privado para adictos, como las terapias privadas o grupos análogos a Alcohólicos Anónimos, por ejemplo, Adictos Anónimos. Es un sinsentido que los Estados del mundo inviertan miles de millones de dólares para reprimir la producción, la posesión y el consumo de marihuana, pero el mundo no se rige siempre por la razón sino por la costumbre y los prejuicios de personas no bien informadas. Entre las personas no bien informadas pueden encontrarse también funcionarios públicos. Cuando el presidente Felipe Calderón abrió la discusión nacional sobre la legalización de la droga, varios funcionarios públicos en México, tanto del gobierno federal como del gobierno del DF, opinaron que no debía legalizarse la droga, porque "no queremos que aumente la adicción en

6 La marihuana es un relajante que también sirve para producir un tipo de textil para ropa y alimento para aves. Su sustancia activa se conoce como tetracannabinol (THC). Según numerosos estudios tiene múltiples efectos terapéuticos para la reducción de dolor, en danos al sistema nervioso, como esclerosis muscular, o en suprimir el vómito en pacientes que reciben quimioterapia para cáncer. También promueve el apetito, por ejemplo, en pacientes con AIDS (Iverson, 2005: pp. 69-72; Andreasson, 1987: pp. 14831486; Degenhardt, 2003: pp. 42-44). 
nuestros jóvenes”, decían. ${ }^{7}$ El silogismo implícito en esta opinión es el siguiente: a) Si se legaliza la droga aumenta la adicción a la droga; b) hemos de prevenir que aumente la adicción a la droga en nuestros jóvenes y adultos; y c) por lo tanto, hemos de evitar la legalización de la droga. Todos podemos estar de acuerdo con la menor de este razonamiento (el punto b), pero la mayor (el punto a) es errónea, como enseñan los ejemplos de Holanda, Portugal y Suiza, razón por la cual la conclusión (el punto c) es contraria a la verdad.

Propongo lo siguiente. Se legalizan la producción, el transporte, la compraventa y la posesión de las soft drugs dentro del territorio nacional, previo registro y licencia de la autoridad competente. Sin embargo, dado que tenemos una larga frontera con los EUA, se prohíbe la exportación de soft drugs. De hecho, la exportación de marihuana a los EUA se desplomó desde que se legalizó la venta terapéutica de ella en más de la mitad de los estados de los EUA, y su producción y compraventa recreativa en cuatro estados. La venta ilegal de marihuana en México constituye el 60\% de las ganancias de las bandas de narcotraficantes en México, de modo que la legalización de la producción y compraventa de soft drugs les quitaría a las bandas del narco el 60\% de sus ganancias, disminuyendo de manera importante su poder corruptor en la sociedad mexicana.

4.2. La aplicación del principio del mal menor al consumo y tráfico de hard drugs

Se despenaliza el consumo de hard drugs y, en consecuencia, también la posesión de cantidades mínimas para el consumo, pero no se legalizarían en México la producción, el transporte, la compraventa, la posesión, y exportación de ese tipo de narcóticos, dado que México es el país por donde pasa la mayor parte de la cocaína que viene de Colombia, Ecuador, Perú y Venezuela, para su venta ilegal en los

7 Tengo los nombres y dichos de estos funcionarios, pero este ensayo no quiere polemizar sino aportar elementos para un diálogo guiado por la razón, por lo que me guardo estos nombres. 
EUA. Se deja en manos del Estado mexicano el monopolio de la producción, importación, y provisión de los hard drugs y sus sustitutos para su administración en centros de rehabilitación.

Los adictos a la droga deben ser tratados como enfermos, no como criminales. Por eso, se despenaliza el consumo de droga, y se crean decenas de centros de rehabilitación, bajo los auspicios de la Secretaría de Salud a nivel federal, y a los adictos se les ofrece un tratamiento gratuito con terapia, durante un encierro voluntario de uno o dos meses, y la entrega gratuita de una dosis de cocaína o heroína, previo registro y prescripción médica, disminuyendo la administración de estas drogas o sus sustitutos gradualmente.

Contrario a lo que suele pensarse, los EUA podrían estar muy interesados en esta solución, porque un obstáculo a la legalización de la droga en los EUA es que ningún político o partido lo puede proponer sin cometer harakiri político. Pero si los adictos a la heroína y a la cocaína pudieran adquirir tratamiento y dosis legales de hard drugs en el Norte de México, se podría mantener la prohibición en los EUA y, sin embargo, los adictos recibirían tratamiento en México. Esta propuesta sí sería políticamente viable en los EUA. En lugar de exportar la guerra contra las drogas a México, los EUA exportarían a México el tratamiento de sus adictos como enfermos, no como criminales. El tráfico de hard drugs se seguiría prohibiendo en México y los EUA, pero los adictos podrían adquirir gratuitamente su dosis en México y curarse de su adicción, sin temor a ser perseguidos por la autoridad.

La exportación y la venta ilícitas de cocaína a los EUA constituían el 30\% de las ganancias de las bandas mexicanas. Pero, últimamente, ha aumentado la exportación de heroína a los EUA. La causa de este fenómeno es que ha disminuido la exportación de marihuana por la sencilla razón de que en casi la mitad de los estados de los EUA la marihuana está permitida para fines terapéuticos y, en cuatro de estos estados, también para fines recreativos, de modo que la iniciativa privada en los EUA ha desplazado a los cárteles mexicanos que introducían marihuana en los EUA.

En respuesta a esta nueva circunstancia, los cárteles mexicanos han aumentado la exportación de heroína (The Economist, 2014: pp. 
25-26). La nueva adicción a la heroína se generó porque se permitió que la iniciativa privada vendiera medicamentos con opio para disminuir el dolor crónico causado por alguna enfermedad, específicamente el medicamento OxyContin. La prescripción de esta pastilla aumentó vertiginosamente en los años '90. Las personas que se hicieron adictas al opio por el consumo de este medicamento venden sus pastillas legales en el mercado negro a $\$ 80$ dólares la pastilla, para luego comprar heroína, más barata. Los cárteles mexicanos han ido sustituyendo el cultivo de marihuana por el cultivo de opio. Aproximadamente 10,000 hectáreas del territorio nacional se destinan al cultivo de opio (heroína). Ahora, México es el tercer país exportador de opio del mundo, sólo después de Afganistán y Birma (Myanmar). Los adictos al opio y la heroína pueden internarse en addiction clinics, centros de rehabilitación, pero a un costo de USD $\$ 27,000$ mensuales, lo que resulta imposible de pagar para la mayoría de los estadounidenses.

Esta historia reciente comprueba tres puntos importantes, que corroboran la validez de mi propuesta de la legalización de la droga:

1) la legalización de las soft drugs (marihuana) socava el negocio de ese tipo de narcóticos de los cárteles de droga; se debe dejar este negocio como negocio legal en manos de la iniciativa privada;

2) no se debe dejar en manos de la iniciativa privada la producción y venta de hard drugs y sus derivados: el Estado debe tener el monopolio, tanto de los hard drugs como de sus derivados médicos, y su administración a adictos, en centros de rehabilitación;

3) el tratamiento en centros de rehabilitación debe ser gratuito.

Al entregar gratuitamente drogas como cocaína y heroína o sus sustitutos o derivados de manera controlada en centros de rehabilitación y disminuyendo gradualmente la dosis a los adictos de México y los EUA, las bandas de narcotraficantes se verían privadas de una parte importante de sus ganancias ${ }^{8}$ y se reduciría grandemente su poder

8 Recuerde el lector que la tasa de adicción (adictos como proporción de consumido- 
económico y corruptor en nuestro país. México vería reducida en importante medida la violencia asociada a la guerra contra el narco, y asociada a la colaboración de autoridades políticas y judiciales con las bandas del narcotráfico.

\section{REFERENCIAS BIBLIOGRÁFICAS:}

AgulLar, Rubén y Jorge Castañeda. 2009. El narco: la guerra fallida. México DF: Punto de lectura.

Andreasson, S. (et al.) 1987. "Cannabis y esquizofrenia: un estudio longitudinal de conscriptos suecos” en The Lancet 2, 1483-86.

Collin, Chantal. 2012. Switzerland's Drug Policy, Prepared for the Senate Special committee on Illegal Drugs, Political and Social Affairs, January 14.

Cuervo Valseca, Fernando. 1994. Principios morales de uso más frecuente: con las enseñanzas de la encíclica. Veritatis Splendor. Madrid: Rialp.

Degenhardt, Louisa (et al.) 2003. "Pruebas de hipótesis sobre la relación entre el consumo de cannabis y la psicosis" en Drug and Alcohol Dependence 71.

European Monitory Centre for Drug and Drug Addiction (EMCDDA). 1995. Drugs Policy in the Netherlands http://www.emcdda.europa.eu/ (Última consulta: $1 /$ ago/2015).

Fernández SÁnchez, Francisco. 2004. "Principio o argumento del mal menor" en Lexicón. Términos ambiguos y discutidos sobre familia, vida y cuestiones éticas. Madrid: Consejo Pontificio para la Familia/Palabra.

Ferragut, Sergio. 2010. Una pesadilla silenciada. México D F: IMDOSOC.

Greenwald, Glenn. 2009. Drug Decriminalization in Portugal. Cato Institute.

IvERSON, Leslie. 2005. "Los efectos a largo plazo de la exposición al cannabis” en Opinión Actual en Farmacología 5, pp. 69-72.

Kandel, D. (et al.) 1997. "Prevalencia y correlatos demográficos de los síntomas de dependencia a los cigarros, el alcogol, la marihuana y la cocaína en la población de los EE. UU.” En Drug and Alcohol Dependence 44, pp. 11-29.

Nadelmann, Ethan. 1995. “Switzerland's Heroin Experiment” en National Review, July 10.

res) es el $66 \%$ para la heroína, $28 \%$ para la cocaína, $18 \%$ para la marihuana, y 12\% para éxtasis, anfetaminas y alcohol. 
ONU, Organización de las Naciones Unidas. 2005. Informe mundial de drogas.

Pablo VI (PAPA). 1968. Carta encícla Humanae Vitae.

Stephens, R. S. 1993. "Los usuarios adultos de marihuana que buscan tratamiento" en Diario de consultoría y psicología clínica 61.

The Economist. 2014. "The Great American Relapse” en The Economist, November 22nd, 2014.

Tomás de Aquino. Summa contra gentiles. Madrid: Biblioteca de Autores Cristianos.

Tomás de Aquino. De Veritate. Turin: Marietti.

Tomás de Aquino. Summa theologica. Madrid: Biblioteca de Autores Cristianos.

Warburton, Clark. 1932. The Economic Results of Prohibition. New York: Columbia University Press. 